\title{
Os MATEMÁticos dA EVoluÇão: COMPLEXIDAdE ESPECIFICADA
}

\author{
Josiney Alves de Souza ${ }^{1}$ \\ Universidade Estadual de Maringá - UEM - Brasil
}

(aceito para publicação em outubro de 2021)

\begin{abstract}
Resumo
Este artigo revisita as incursões históricas de matemáticos na teoria evolucionária. O objetivo é apresentar algumas reflexões de tratativas matemáticas na discussão da complexidade presente na evolução. Os matemáticos propõem caminhos alternativos por coevolução mútua, metabiologia, ou design, infligindo desafios mais profundos na compreensão dos processos evolutivos de organismos vivos.
\end{abstract}

Palavras-chave: Teoria da evolução; mecanismo darwiniano; matemática; complexidade.

[THE DARWIN MATHEMATICIANS: SPECIFIED COMPLEXITY]

\begin{abstract}
This article revisits the historical incursions of mathematicians into evolutionary theory. The purpose is to present some mathematical investigations in the discussion of the complexity, present in the evolution. The mathematicians propose alternative ways by mutual coevolution, metabiology, or design, exposing deeper challenges in understanding the evolutionary processes of living organisms.
\end{abstract}

Keywords: Evolution theory; Darwinian mechanism; mathematics; complexity.

\footnotetext{
${ }^{1}$ Bolsista de Produtividade do CNPq - (processo no 303011/2019-0)
} 


\section{Introdução}

O avanço tecnológico do Século XX causou enorme impacto na biologia evolutiva, uma vez que os computadores eletrônicos ajudaram os cientistas a testarem o mecanismo darwiniano. Matemáticos de renome tomaram frente em pesquisas e desempenharam papel fundamental no fornecimento de análises críticas dos processos evolutivos (SOUZA, 2016). O interesse dos matemáticos pela teoria evolucionária é voltado principalmente para a possibilidade de uma formalização da seleção natural, baseado em um algoritmo evolutivo que utiliza um processo matematicamente descritível de tentativa e erro para produzir complexidade. De forma geral, os matemáticos estimam que o mecanismo darwiniano seria viável somente se hipóteses muito especiais fossem assumidas. Os resultados da análise matemática sugerem uma reformulação teórica da evolução, aprimorada nas leis da natureza e no componente metafísico.

A partir de uma perspectiva filosófica, o artigo Os Matemáticos da Evolução (SOUZA, 2016) tratou desse assunto com detalhes históricos das incursões de matemáticos na teoria evolucionária e discutiu o papel fundamental da matemática no aprimoramento do mecanismo darwiniano. Esse estudo foi inspirado no encontro histórico ocorrido em 1966, no Instituto Wistar de Anatomia e Biologia da Filadélfia, nos Estados Unidos, onde matemáticos, biólogos e outros cientistas de áreas afins se reuniram para avaliar se o neodarvinismo era matematicamente viável. A conferência recebeu o nome de "Mathematical Chalenges to the Neodarwinian theory of Evolution" e foi presidida pelos eminentes biólogos britânicos Conrad Hal Waddington (1905-1975) e sir Peter Medawar (1915-1987). Os biólogos foram confrontados por análises críticas de três principais matemáticos: Stanley Ulam (1909-1984), Marco Schützenberger (1920-1996) e Murray Eden (1920-2020). Em linhas gerais, os matemáticos apresentaram argumentos contundentes sobre a inviabilidade matemática de se produzir complexidade por meio de processos aleatórios e seleção natural, com o parecer de que o neodarvinismo não era matematicamente defensável.

O encontro no Instituto Wistar causou um enorme impacto no meio científico e influenciou o surgimento de outros matemáticos interessados em estudar o mecanismo darwiniano. Estudos estatísticos de probabilidade e construções de algoritmos evolutivos se tornaram muito comum, o que de certa forma contribuiu significativamente com a teoria evolucionária. Fred Hoyle (1915-2001) e John Lennox são exemplos notáveis destes matemáticos que analisaram os estudos evolucionistas subsequentes à conferência na Filadélfia. Eles foram unânimes em defender que a vida e as espécies de seres viventes não surgiram por meio de processos aleatórios. Em resposta ao montante de pareceres desfavoráveis, os darwinistas reconheceram a impossibilidade de o acaso gerar a vida, mas defenderam que a seleção natural envolvia outros aspectos como a necessidade, a mutação, a deriva genética e outros parâmetros relacionados, o que determinou um significativo aperfeiçoamento na teoria evolucionária. Mas o conceito taquigráfico de seleção natural continuou encontrando obstáculos, levantados principalmente pelos conceitos de entropia e sistemas caóticos. Os matemáticos alertaram sobre a possibilidade de pequenas variações tipográficas gerarem confusões ou incompreensibilidade, sendo expressamente inconveniente basear a evolução em mutações genéticas. Evidentemente, a seleção natural 
necessita da vida preexistente para funcionar, ficando assim limitada pelo enigma da origem da vida. Sobre isto, os matemáticos concluíram que processos naturais são bons para transmitir informação, mas são incapazes de gerar informação, e isto se consolidou como um dos maiores entraves da síntese neodarwiniana.

Como a teoria evolucionária pode resolver ou contornar este problema? Em 1999, exatos 33 anos após o histórico encontro em Wistar, matemáticos, físicos, biólogos e filósofos se reuniram novamente para discutir os avanços científicos sob a nova perspectiva da complexidade na teoria da informação. O simpósio de pesquisa intitulado "Complexity, Information, and Design: A Critical Appraisal” ocorreu em Santa Fe, no Novo México, com o apoio do John Templeton Foundation, onde os participantes exploraram as questões mais amplas, que são desmembradas pela teoria da informação e estudos de complexidade, em particular seu impacto em nossa visão de mundo e na percepção de nosso lugar na natureza, de sentido e de propósito. O encontro em Santa Fe foi mais um marco histórico das incursões de matemáticos na teoria evolucionária, onde as discussões incluíram uma proposta progressiva para os desdobramentos da teoria da evolução.

O presente artigo seleciona os principais aspectos dessas discussões, compartilhando as ideias primordiais dos matemáticos. Veremos a proposta da coevolução mútua apresentada pelo matemático Ian Stewart, que amplia enormemente o campo de trabalho da teoria evolucionária. Stewart também propõe uma solução para o conflito entre a biologia evolutiva e as leis da física. Conheceremos o trabalho entusiástico do matemático Gregory Chaitin na tentativa de formular uma matemática da evolução por meio da metabiologia - a teoria evolucionária dos softwares artificiais. Em outra direção, o matemático Willian Dembski nos apresenta uma demonstração formal de que algoritmos evolucionários não podem gerar complexidade especificada, a menos que haja algum tipo de direcionamento inteligente.

\section{Complexidade especificada e código genético}

Segundo a física moderna, existe complexidade em todas as escalas, desde os delicados padrões de filigrana na superfície de Júpiter até a majestade organizada de galáxias espirais. Em uma célula viva, evidencia-se complexidade em suas elaboradas moléculas personalizadas, muitas contendo milhares de átomos dispostos com precisa especificidade. Os físicos esperam que as leis subjacentes da natureza sejam amalgamadas em um único esquema matemático abrangente, o que permitiria um entendimento preciso de complexidade. Enquanto este sonho não acontece, a complexidade torna difícil a concepção do reducionismo, visto que, na opinião de muitos cientistas, qualidades complexas como a vida e o pensamento têm um significado genuíno que, mesmo em princípio, não pode ser reduzido ao comportamento de partículas subatômicas (DAVIES, 2003, p. 5).

Entretanto, a disponibilidade de modelagem rápida de computadores permitiu que sistemas complexos fossem estudados em grande generalidade, sustentando a promessa de que sistemas tão díspares como economias, sistemas imunes e ecossistemas podem estar em conformidade com princípios matemáticos comuns. Os exemplos mais conhecidos de sistemas complexos são os sistemas caóticos e os auto-organizantes. Sistemas caóticos possuem sensibilidade com respeito às condições iniciais, de forma que estados muito 
próximos divergem rapidamente em sua evolução. No entanto, em longo prazo, estados distintos se aproximam, o que torna um sistema caótico completamente imprevisível. Por outro lado, um sistema auto-organizante salta espontaneamente de um estado relativamente inexpressivo a um estado de maior complexidade organizada, atribuindo um aspecto criativo, diferente de um sistema caótico.

Embora o conceito de complexidade seja bem intuitivo, não existe uma definição formal de complexidade que seja geralmente aceita, muito menos uma forma universal de quantificá-la. Entretanto, o matemático Gregory Chaitin fornece uma definição matemática precisa de complexidade que procura ir além da simples designação de "ser complexa" e caracterizar qualidades sutis como organização e adaptação. Baseando-se na teoria da computação digital, Chaitin procura quantificar a complexidade de um sistema físico em termos da dificuldade de simulá-lo ou descrevê-lo com um computador digital, o que abre caminho para fazer distinções precisas entre a complexidade organizada e aleatória (CHAITIN, 2003). Em vista da teoria de probabilidade, complexidade poder ser interpretada como improbabilidade, de forma que sistemas demasiadamente complexos são muito improváveis de ocorrer por pura sorte.

A noção de complexidade ascende uma luz para o problema da origem e evolução da vida, mas, ao mesmo tempo, inflama o desafio da origem da informação biológica, considerada como informação complexa especificada. Além da característica da improbabilidade, uma informação complexa especificada é também irredutível, de forma que não apresenta padrão de repetição. Para o eminente biólogo Stuart Kauffman, o mecanismo darwiniano pode gerar alguma complexidade biológica desde que a ele seja adicionado princípios de auto-organização. Para o matemático Willian Dembski, a informação biológica não pode surgir através de um algoritmo evolutivo do tipo darwiniano, a menos que um agente inteligente seja considerado (DEMBSKI, 2003).

Enquanto a teoria darwiniana da evolução conflita com a segunda lei da termodinâmica, o conceito de complexidade sugere que o indicador mais preciso da história cósmica é o enriquecimento progressivo dos sistemas físicos associados ao crescimento da complexidade. De acordo com o matemático Ian Stewart, em vez da entropia, outra seta do tempo - uma progressiva - aponta na direção de maior complexidade, caracterizada por uma tendência geral ou lei da natureza. A sugerida "quarta lei da termodinâmica" seria mais coerente com o fenômeno da gravitação, visto que sistemas gravitacionais tendem a crescer em complexidade (STEWART, 2003).

O design inteligente é a assertiva de que uma causa inteligente é responsável pela complexidade da vida e que se pode detectar essa causa empiricamente. Estudos do design inteligente discutem a possibilidade das formas de inteligência serem resultados de processos evolutivos. A questão sobressalente versa sobre a existência de padrões explicativos da inteligência em sistemas biológicos. Tradicionalmente, a inteligência do ser humano é definitiva, não cabendo um processo evolutivo em sua constituição. Antes da era digital, o estudo da mente ou da inteligência era considerado anticientífico, pois não podia ser testado e nem modelado. No entanto, com a teoria da informação, um ramo bem estabelecido da engenharia e ciências matemáticas, a informática evolutiva eliminou essa dificuldade de introduzir o conceito de inteligência em estudos científicos. Pesquisas em informática mostraram que padrões normalmente atribuídos à inteligência, quando 
decorrentes de um processo evolutivo, devem ser referidos a fontes de informação externas a esse processo. Tais fontes de informação podem ser o resultado de outros processos evolutivos mais profundos, implicando uma cadeia de processos transmissores de informação. Onde tal cadeia regressiva de informações se inicia e o que permite que esses processos evolutivos produzam tais fontes de informação? Necessariamente, a regressão implica uma incompletude fundamental na capacidade da causalidade física de produzir as informações necessárias. Sem considerar qualquer violação da causalidade física ao longo dos processos, aponta-se para a necessidade de uma fonte de informação de uma inteligência primordial. Essa é uma das justificativas lógicas para o design inteligente.

No campo da biologia teórica, a origem da informação biológica é a chave para se entender a origem e evolução da vida, de modo que a característica de um código genético é um tipo de complexidade especificada (DAVIES, 2000, p. 112). As conhecidas leis da física e da química por elas mesmas podem no máximo explicar a especificação, mas não a complexidade. Por outro lado, a contingência pode explicar a complexidade, mas não a especificação. Por esse motivo, o código genético é enigmático, pois possui uma complexidade especificada.

\section{Matemática e evolução}

Discorremos agora sobre as incursões dos renomados matemáticos que se reuniram em Santa Fe para discutir o papel da complexidade na compreensão do mundo.

\section{Ian Stewart}

Ian Nicholas Stewart é um matemático britânico e escritor de ciência popular e ficção científica. Seu talento para as ciências exatas foi percebido muito cedo no período escolar, o que lhe rendeu uma bolsa de estudos para estudar na University of Cambridge, onde obteve o grau de bacharel em matemática, em 1966. Stewart então foi para a University of Warwick, onde completou seu doutoramento em matemática no ano de 1969, tendo o conceito de álgebra de Lie como assunto principal de sua tese. ${ }^{2}$ Depois de seu doutoramento, assumiu um posto acadêmico em Warwick, onde passou a contribuir intensamente com a teoria da catástrofe. Stewart recebeu o título de Professor Emérito da University of Warwick e atualmente é diretor do Mathematics Awareness Centre daquela universidade.

Durante sua carreira, Stewart foi editor da revista Manifold e colunista da revista Scientific American. Fez visitas acadêmicas na Alemanha, na Nova Zelândia e nos Estados Unidos. Publicou mais de 140 influentes artigos científicos e cerca de 60 livros textos de matemática, de ciência popular e de ficção científica, incluindo os aclamados Catastrophe Theory and its Applications (1978), Complex Analysis: The Hitchhiker's Guide to the Plane (1983), Nature's Numbers: The Unreal Reality of Mathematics (1996), Life's Other Secret: The New Mathematics of the Living World (1998), The Science of Discworld (1999), Galois Theory (2000), Algebraic number theory and Fermat's last theorem (2002) e The Founda-

${ }^{2}$ Subideals of Lie Algebras, 1969.

RBHM, Vol. 21, nº 41, pp. 89-108, 2021 
tions of Mathematics (2015). Recebeu várias condecorações, entre elas, a medalha Michael Faraday, em 1995, e a medalha Christopher Zeeman, em 2008. Foi eleito membro da Sociedade Real em 2001. Na era digital, Stewart ganhou popularidade mundial devido ao seu iPad app, Incredible Numbers by Professor Ian Stewart, de 2014. Outros dados da biografia de Ian Stewart podem ser encontrados em sua homepage. ${ }^{3}$

As incursões científicas de Stewart nas áreas biológicas, inevitavelmente, levaramno a discutir a teoria da evolução. Em Figments of Reality, com coautoria do biólogo Jack Cohen, Stewart discutiu questões de difícil tratamento pelas vias do pensamento evolucionista de Darwin: O que aconteceu no início do universo? Como a vida se originou? Como a inteligência evoluiu? Como surgiu a cultura? Que tipos de seres são conscientes? O que é livre arbítrio? Ele foi além da tentativa de responder a essas perguntas, mas também tentou conectá-las em uma história coerente sobre como a evolução do universo levou ao tipo de mundo em que tais perguntas podem ser feitas. "O que é mente e como ela chegou aqui?” foi a pergunta central do discurso. A resposta dada foi: "Mentes são frutos da realidade, processos acontecendo dentro de estruturas feitas a partir de matéria comum cujo comportamento evoluiu a fim de imitar, modelar e manipular processos naturais" (STEWART, 1997, p. x). Elas existem no cérebro, mas estão ligadas à realidade através de interações com o meio ambiente, outras mentes, cultura e evolução. Os processos pelos quais essas interações ocorrem são denominados de complexidade e simplicidade, cuja conivência é considerada como uma espécie de coevolução mútua entre dois processos inicialmente separados. A inteligência humana e a cultura humana constituem um caso de coevolução mútua, que devido ao seu inextricável entrelaçamento, tornam-se um único processo muito mais complexo. Neste caso particular, o início da cumplicidade entre inteligência e cultura humana pode ser interpretado pela evolução de maneiras não genéticas, mas pelas transmissões de conhecimentos, hábitos e comportamentos, de geração em geração. A evolução da mente humana se daria dessa forma, pois mente não é apenas uma questão de estrutura cerebral sofisticada, mas algo que surgiu do processo de passar o comportamento por meio do ensino e da aprendizagem.

Conforme a mente evolui, ela se torna cada vez mais complexa - essa foi a chave do pensamento de Stewart. Para essa evolução, a consciência é fundamental, pois quanto mais vívidos são os sentimentos que acompanham a dor, a percepção das cores e outros fenômenos mentais, mais efetivamente o ser consciente reagirá às suas impressões sensoriais e mais provável é que ele sobreviva. Neste tratamento, no entanto, o matemático às vezes superestima o poder da evolução. Ainda em Figments of Reality, Stewart adere ao pressuposto da adaptação celular, acreditando que a maioria dos traços de organismos biológicos surgiu porque esses traços são úteis para a sobrevivência, e que a evolução tem a capacidade plena de projetar tais traços. Ao esquematizar o processo evolutivo do cérebro, ele afirma: "O que quer a evolução, e pode obter, ela consegue" (STEWART, 1997, p. 136). Mas Stewart não faz qualquer ressalva sobre as correntes controversas na biologia evolutiva quanto à quantidade de exigibilidade que a seleção natural tem e quanto poder tem para moldar a adaptação biológica.

\footnotetext{
${ }^{3}<$ https://ianstewartjoat.weebly.com/>.
} 
Apesar de sua simpatia com a biologia evolutiva, Stewart deixa o indicativo de que o mecanismo darwiniano não passa no teste epistemológico e carece de profundos aperfeiçoamentos. Voltando ao conceito de coevolução, a cumplicidade da inteligência e da cultura humana é um exemplo preeminente de um processo de auto-organização. No entanto, a abordagem reducionista tradicional da ciência não pode explicar o comportamento emergente dos sistemas ditos auto-organizados, uma vez que os elos microscópicos da causalidade são muito complicados para eles serem elucidados (MITCHELL, 1997). Para descrever tais sistemas, Stewart sugere uma abordagem diferente, na qual um vocabulário macroscópico apropriado deve ser constituído. O estudo do conceito de complexidade procura desenvolver tal vocabulário. Segundo afirma o biólogo Stuart Kauffman, tratando-se de geração de complexidade biológica, os princípios da auto-organização são mais poderosos do que o mecanismo darwiniano, uma vez que os sistemas vivos tem a capacidade de literalmente assumir uma vida própria e se comportar como agentes autônomos em vez de meros escravos das leis da física e da química (KAUFFMAN, 2003, p. 48).

Na era digital, o conceito de informação é o cerne da descrição computacional da natureza. Em biologia, toda a informação sobre um organismo vivo é carregada no gene. Atualizando-se com o contexto digital, a visão neodarwiniana da evolução passou a se concentrar no papel do gene e se basear em modelos tradicionais de polimorfismo. Dessa forma, o modelo neodarwiniano não dá espaço para o conceito da auto-organização. Entretanto, Stewart notificou que modelos baseados em fenótipos que incluem efeitos não lineares e coletivos sugerem que a evolução pode de fato ser vista como um processo pelo qual o ecossistema se auto-organiza. A partir desse ponto, foi possível esclarecer algumas das questões em torno do papel da auto-organização, incluindo novas abordagens para as pressuposições de aptidão e seleção de espécies. Juntamente com J. Skår e P. Coveney, Stewart apresentou modelos que representam o fenômeno da especiação como uma bifurcação de quebra de simetria, mas em diferentes contextos matemáticos, incluindo sistemas dinâmicos determinísticos, sistemas dinâmicos estocásticos e sistemas dinâmicos discretos (SKÅR, 2003). Suas conclusões foram convincentes, apesar da diversidade dos modelos.

A partir dessas pesquisas, Stewart se tornou um grande colaborador da teoria evolucionária. Estendendo o ambiente de discussão, pesquisou também sobre as principais controversas envolvendo os pressupostos evolucionistas e as leis físicas. A segunda lei da termodinâmica associa a qualquer sistema termodinâmico fechado uma quantidade conhecida como entropia, a qual usualmente é interpretada como uma medida de desordem. Conforme o tempo passa, a entropia do sistema tende a crescer. No entanto, diferentemente de um universo regido por essa lei física, a biosfera dá aparências de evoluir para uma forma cada vez mais sofisticada de organização. Isto não contradiz a segunda lei da termodinâmica, pois a biosfera é dirigida principalmente pela radiação solar, o que não caracteriza um sistema termodinâmico fechado. Por outro lado, a física não fornece razões claras da tendência para maior organização de certos sistemas termodinâmicos com input de energia. Pelo contrário, exemplos como água fervendo em um recipiente mostram que sistemas termodinâmicos não fechados podem apresentar entropia crescente. Portanto, a 
segunda lei da termodinâmica é inútil para sistemas não fechados e, portanto, é inaplicável na biologia evolutiva.

Para discutir sobre esse assunto, Stewart associa organização com complexidade e adere à proposta de Kauffman sobre uma "quarta lei da termodinâmica" - princípio físico geral suplantando as três leis da termodinâmica - que explicaria o crescimento da complexidade na biosfera (KAUFFMAN, 2000). Esta tese pode ser argumentada de forma bastante convincente, embora muitos biólogos evolucionistas acusem a falta de evidências para o crescimento da complexidade no mundo biológico. Em Second Law of Gravitics and Fourth Law of Thermodynamics, Stewart inclui a ideia de uma segunda lei da gravidade que quantifica o crescimento da complexidade de sistemas gravitacionais, uma vez que esses sistemas tendem a aumentar seu grau de organização. Dessa forma, os sistemas gravitacionais fornecem uma excelente mesa-de-testes para a quarta lei da termodinâmica, e uma segunda lei da gravidade teria um papel fundamental. O matemático sugere a definição de uma medida de complexidade gravitacional associada com tal segunda lei da gravidade. Esse novo conjunto de leis permitiria formalizar ou explicar a tendência de sistemas biológicos em aumentar seu grau de organização.

\section{Gregory Chaitin}

Gregory John Chaitin é um matemático e cientista da computação argentino-estadunidense, um dos fundadores da complexidade algorítmica, com importantes contribuições para a teoria da informação algorítmica e metamatemática. De uma família de origem judaica, frequentou o Bronx High School of Science e o City College of New York, onde desenvolveu as teorias que levaram à sua descoberta independente da complexidade de Kolmogorov na década de 60. ${ }^{4}$ Em 1995, recebeu o título de doutor Honoris Causa em ciência da computação pela University of Maine. Em 2002, recebeu o título de professor honorário da Universidad de Buenos Aires. Dois anos mais tarde, foi premiado com a Medalha Leibniz pelo Wolfram Research. Em 2009, foi condecorado com o título de doutor Honoris Causa em filosofia e humanidades pela Universidad Nacional de Córdoba. Foi professor visitante na University of Auckland e pesquisador do Thomas J. Watson Research Center da IBM, em Nova Iorque. Atualmente, é professor da Universidade Federal do Rio de Janeiro.

Chaitin escreveu mais de dez livros que foram traduzidos para cerca de 15 idiomas, incluindo os celebrados Algorithmic Information Theory (1987), The Limits of Mathematics (1998), The Unknowable (1999), Exploring Randomness (2001) e Conversations with a Mathematician (2002). Tornou-se um matemático muito conhecido devido a várias descobertas importantes: o algoritmo de Chaitin, que aloca registros para coloração de grafos; a constante de Chaitin - ou número $\Omega$ - que expressa a probabilidade de um programa aleatório ser interrompido; um novo teorema da incompletude, contrapondo-se ao clássico teorema da incompletude de Gödel.

\footnotetext{
${ }^{4}$ Ray Solomonoff havia elaborado propostas relacionadas em 1960 de forma que esta teoria também é conhecida como a Teoria de Chaitin-Kolmogorov-Solomonoff.
} 
Ao longo de seus estudos com a teoria de algoritmos, Chaitin também escreveu sobre metafísica e filosofia da matemática, chamando a atenção de matemáticos, filósofos e biólogos para problemas fundamentais em criatividade matemática e filosofia digital. Em epistemologia da matemática, ele afirma que suas descobertas na lógica matemática e na teoria da informação algorítmica mostram que existem "fatos matemáticos que são verdadeiros sem motivo, que são verdadeiros por acidente" (CHAITIN, 2003). Propõe que os matemáticos devem abandonar qualquer esperança de provar esses fatos matemáticos e adotar uma metodologia quase empírica. Suas pesquisas também contribuíram para a biologia evolutiva e a neurociência - principalmente sobre estudos da mente.

Chaitin demonstra uma fé inabalável no poder explicativo da matemática moderna. Nesta perspectiva, a partir de 2009, desbravou o campo da metabiologia, onde estuda a teoria da evolução dos softwares artificiais. Inconformado com a falta de formalidade matemática para estudos da evolução - o que considerava um "escândalo" para os matemáticos - propôs a teoria da informação algorítmica como a chave para solucionar problemas de biologia evolutiva e desenvolveu um modelo algorítmico para o mecanismo darwiniano. Acreditando ter atendido com êxito uma demanda científica, não se constrangeu em incluir uma definição formal de "vida", assim como sua origem e evolução. Em 2012, reuniu os resultados de seus esforços no livro Proving Darwin: Making Biology Mathematical, que foi publicado em resposta ao The Devil's Delusion, de seu amigo David Berlinski. Mesmo discordando das proposições do colega, Chaitin mantém uma atitude de respeito para com os proponentes do design inteligente, mas deixa clara sua posição: "Por muitos anos ponderei que é um escândalo matemático não termos uma prova de que a evolução darwiniana funciona” (CHAITIN, 2012, p. 53).

Chaitin se mostrou bastante confiante ao apresentar seu trabalho em Proving Darwin. Ele justifica sua motivação observando que se a teoria darwiniana da evolução é de fato fundamental como os biólogos pensam, então deve existir uma teoria matemática da evolução - geral e abstrata - que capture a essência da teoria de Darwin e a desenvolva matematicamente (ibidem, 2012, p. 9). Tendo em vista tentativas prévias de atender esse caso por meio da teoria dos jogos ou processos estocásticos, Chaitin introduz, alternativamente, a metabiologia como base teórica para sua proposta de formalizar a teoria da evolução por seleção natural. Conforme sua definição, metabiologia é "um campo paralelo à biologia lidando com a evolução indiscriminada de softwares artificiais (programas de computador) ao invés de softwares naturais (DNA)” (ibidem, 2012, p. xvi). De forma geral, a metabiologia usa ferramentas de matemática discreta não axiomática, contendo uma hierarquia infinita de verdades, cada uma gerando informações fundamentais para a outra - prática procedente dos resultados de Gödel e Turing.

A metabiologia é considerada por Chaitin o seu melhor esforço em encontrar um ideal platônico da evolução (ibidem, 2012, p. 66). Diferentemente de tentativas frustradas em provar o mecanismo darwiniano por simulações artificiais, ele faz questão de observar que sua proposta é de uma matemática pura e consistente, com potencial de produzir uma prova formal para a existência de formas matemáticas abstratas de vida, além de possibilitar 
discussões fisolóficas. Neste ponto, Chaitin faz alusão da metabiologia como um tipo de "biologia pitagoriana" (ibidem, 2012, p. 12). ${ }^{5}$

Assim como deve ser todo bom modelo matemático, a construção da metabiologia é de simples compreensão, pelo menos para um público suficientemente instruído. Em princípio, Chaitin define o vocabulário da biologia evolutiva: organismo, DNA, mutação, aptidão e evolução. Em seguida, associa esse vocabulário a conceitos de computação científica: organismo, DNA, mutação, aptidão e evolução são, respectivamente, tratados por software natural, linguagem de programação natural, um programa modificador de um organismo e caminho arbitrário no espaço de todos os possíveis programas. O organismo é modelado por um programa $\mathrm{P}$ de $n$-bits - uma máquina de Turing. ${ }^{6} \mathrm{O}$ nível de adaptação desse organismo é interpretado por um número natural F calculado por P. Na sequência, P é sujeitado a uma mutação arbitrária por um programa modificador $\mathrm{M}$, o qual retorna um programa descendente P', de mesma dimensão $n$-bits, mas com um nível mais alto de adaptação F'. Para modelar a competição entre gerações de organismos, Chaitin usa o algoritmo do castor para iniciar e dirigir o processo evolucionário, representando a habilidade da biosfera em gerar novas soluções em resposta à influência evolucionária. ${ }^{7}$ Nesta modelagem, a criatividade matemática corresponde à criatividade da natureza.

O programa modificador $\mathrm{M}$ no modelo de Chaitin é o elemento mais importante para gerar novidades evolutivas. A regra para a escolha de $\mathrm{M}$ está de acordo com a distribuição de probabilidade, onde a probabilidade de escolha do modificador é proporcional ao seu comprimento em bits. $\mathrm{O}$ tempo $T$ necessário para o programa $\mathrm{P}$ alcançar o maior nível de adaptação deve satisfazer $n^{2} \leq T \leq n^{3}$. Neste cenário hipotético, Chaitin alega que o mecanismo darwiniano é capaz de produzir objetos com cada vez mais alto grau de adaptação e conclui que esse processo com nível ascendente de adaptação é uma boa interpretação matemática para a característica de "estar vivo" (ibidem, 2012, p. 49). Em outras palavras, ele considera que a habilidade de evoluir por seleção natural é uma condição suficiente para ser um "objeto vivente".

A principal crítica sobre o modelo de Chaitin se refere ao seu grau de generalidade em matemática pura, que aparentemente torna impossível qualquer aplicação prática. A metabiologia não trata de sistemas que são sujeitos às leis naturais, ou seja, os sistemas físicos. Isto significa que o modelo de Chaitin não considera as influências do meio ambiente, sendo assim inaplicável. O doutor em filosofia Radosław Siedliński salienta que

\footnotetext{
${ }^{5}$ Alusão a Escola Pitagórica, influente corrente filosófica grega que foi fundamental para o desenvolvimento da matemática.

${ }^{6}$ Máquina de Turing é um dispositivo teórico conhecido como máquina universal, que foi concebido pelo matemático britânico Alan Turing (1912-1954), muitos anos antes de existirem os modernos computadores digitais. Mais precisamente, é um modelo abstrato de um computador, que se restringe apenas aos aspectos lógicos do seu funcionamento (memória, estados e transições).

${ }^{7}$ Considerando uma máquina de Turing com alfabeto binário $\{0,1\}, n$ estados operacionais e um estado adicional de parada, acione a máquina em uma fita limpa (todas posições com 0) até que ela pare. Anote o número de 1s que sai na fita. Entre todas as possibilidades, encontre uma máquina de Turing que deixa o maior número de 1s em sua fita antes de parar. A função do algoritmo do castor é definida pelo número de 1s que essa máquina de Turing imprime.
} 
o procedimento é, na verdade, incomputável (SIEDLIŃSKI, 2016). Dado um programa P, o procedimento precisa garantir que o programa modificador $\mathrm{M}$ sempre produza um descendente P', ou seja, que ele sempre interrompa a iteração sobre P, além de elevar o nível de adaptação de F para F'. Ciente do problema, Chaitin afirma ser necessário recorrer a informações externas fazendo uso do Oracle - o que é incomputável - mas não se mostra interessado em tentar projetar um modelo de implementação em alguma linguagem de programação existente ou de execução em computadores reais.

As críticas de Siedliński são importantes para se entender o quanto é difícil ratificar a teoria darwiniana da evolução. A metabiologia considera um domínio ilimitado de recursos e o tempo infinito, o que consiste de um pressuposto não realístico e, teoricamente, permite que os procedimentos atinjam qualquer resultado que se queira. Chaitin considera que este contratempo é temporário:

"Modelos mais realistas limitarão o tempo de execução dos programas e, assim, evitarão a necessidade de oráculos. Espero que haja uma troca entre o realismo biológico e o que pode ser provado: Quanto mais realista o modelo, mais teremos que confiar em simulações de computador em vez de provas.” (CHAITIN, 2012, p. 89)

Entretanto, outros problemas da metabiologia são ainda mais sérios. É o caso da hipótese do nível crescente de adaptação dos organismos (programas). No modelo de Chaitin, as mutações não influenciam negativamente na sobrevivência do organismo, descartando qualquer possibilidade de picos adaptativos locais em que a evolução poderia ficar estancada. Chaitin reconhece que seu modelo é apropriado para descrever a evolução darwiniana (e não a involução): "O cenário de adaptação tem que ser muito especial para a evolução darwiniana funcionar” (ibidem, 2012, p. 68). Isto significa que o procedimento de Chaitin não é indiscriminado, mas sim dirigido, o que é antidarwiniano (SIEDLIŃSKI, 2016, p. 142). Outro problema com esse procedimento é sua limitação a um simples organismo sem a presença de uma população. Evidentemente, somente em uma população pode existir variedade de indivíduos, competição por recursos limitados e adaptação ao ambiente (ibidem, 2016. P. 143).

Siedliński também aponta o aspecto genocêntrico da metabiologia. Nos últimos anos, a biologia evolutiva deixou de ostentar os organismos como as unidades fundamentais da vida, substituindo-os pelos genes. Depois da descoberta do DNA, o genótipo passou a ter maior interesse do que o fenótipo, uma vez que toda a teoria da informação pode ser aplicada ao código genético. Forma de investigação completamente distinta das pesquisas originais de Darwin, que evidentemente eram baseadas nas características observáveis ou caracteres dos organismos ou populações. Inspirado por Richard Dawkins, Chaitin assume o genocentrismo: "Eu tomo de Dawkins sua ênfase em genes. Quem se importa com corpos??” (CHAITIN, 2012, p. 48). Ele declara que "tudo o que importa é a informação, tudo o que importa é onde você recebe as instruções para fazer algo. A energia vai cuidar de si mesma!” (ibidem, 2012, p. 19). O posicionamento genocêntrico obrigou Chaitin a alterar radicalmente a definição de vida: "vida é um sistema que tem hereditariedade e 
mutações e evolui pela seleção natural” (ibidem, 2012, 48). Uma definição bem diferente da conceituação usual de vida, visto que itens fundamentais foram excluídos - variação individual e reprodução - e, em lugar desses, a mutação foi incluída, por motivos óbvios (MAYNARD, 1986). Se vida é tudo o que evolui, então uma informação é um organismo vivo, segundo a definição de Chaitin (SIEDLIŃSKI, 2016, p. 145).

A conclusão de Siedliński é que a metabiologia é extremamente restringida às informações do código genético e completamente privada das informações externas ao DNA. Na verdade, a metabiologia é a ciência da computação teórica vestida de uma nova roupagem, em que a sequência processual padrão programa-execução-produto é interpretada por DNA-desenvolvimento-organismo (ibidem, 2016, p. 146). Ou seja, o modelo de Chaitin é somente uma visão alternativa de uma teoria já existente e, portanto, não é revolucionário e muito menos capaz de descrever a complexidade da vida e de sua evolução. "A teoria matemática geral da evolução darwiniana ainda continua sendo uma canção do futuro, e os biólogos parecem permanecer pessimistas moderados na questão da capacidade de formulá-la” (ibidem, 2016, p. 147). Siedliński expõe seu parecer final indicando que a metabiologia deve ser tratada como uma mera expressão das visões filosóficas de Chaitin e não necessariamente uma tentativa séria de contribuir com algo novo e vital para o campo da biologia teórica (ibidem, 2016, p. 148).

Vale ressaltar que é comum, em matemática pura, dar ênfase ao abstrato. Além disso, a modelagem matemática procura sempre escolher o padrão mais simples possível, segundo o princípio da Navalha de Ockham. Abstendo-se de qualquer julgamento das supostas influências filosóficas, a proposta de Chaitin parece sincera e condizente com seu objetivo de estabelecer um modelo matemático germinal que possa impulsionar estudos posteriores. Contudo, deve-se reconhecer que nenhuma teoria pode se adaptar a todos os fatos.

\section{William Dembski}

William Albert Dembski é um matemático, filósofo e teólogo estadunidense e um dos principais proponentes do design inteligente. Nascido em Chicago, e de família católica, seu período escolar foi destacado por seu talento para a matemática. Na universidade, estudou psicologia, estatística, matemática e filosofia. Em 1983, obteve o grau de mestre em estatística pela University of Illinois at Chicago. Dois anos depois, concluiu o mestrado em matemática pela University of Chicago. Em 1993, recebeu o grau de mestre em filosofia pela University of Illinois at Chicago. Doutorou-se em matemática pela University of Chicago, em 1988, e em filosofia pela University of Illinois at Chicago, em 1996. Completando sua ampla formação acadêmica, recebeu o título de mestre em divindade e teologia pela Princeton Theological Seminary, ainda em 1996.

Dembski foi um membro sênior do Center for Science and Culture, no Discovery Institute. Escreveu diversos livros sobre design inteligente, incluindo The Design Inference (1998), Intelligent Design: The Bridge Beween Science \& Theology (1999), The Design Revolution (2004), The End of Christianity (2009) e Intelligent Design Uncensored (2010). Entre suas organizações científicas, Dembski difundiu em 2001 a International Society for Complexity, Information and Design, da qual é diretor executivo. Em 2007, Dembski 
desempenhou um papel fundamental na fundação do Evolutionary Informatics Lab, em parceria com o professor de engenharia Robert J. Marks II da Baylor University. Dembski também é membro da American Scientific Affiliation e da American Mathematical Society. Aposentou-se em 2016, depois de 20 anos como pesquisador do Discovery Institute.

A primeira contribuição significativa de Dembski para o design inteligente foi o artigo Randomness by Design, de 1991. Mas foi sua contribuição em The Creation Hypothesis que influenciou fortemente sua especialidade no conceito de complexidade (DEMBSKI, 1994). Dois outros contribuintes desse livro, Charles Thaxton e Walter Bradley, discutiram a "detecção de design" e redefiniram a complexidade especificada como forma de medir informações. Essas ideias levaram à noção de complexidade especificada de Dembski, que ele desenvolveu com profundidade no aclamado The Design Inference: Eliminating Chance through Small Probabilities, uma revisão de 1998 de sua tese de doutorado em filosofia. Ele atribuiu à complexidade especificada o significado de uma complexidade irredutível, e postulou que esta pode ser estudada pelas vias da teoria de probabilidade. Tendo como base a teoria da informação de Shannon, o conceito de complexidade denota uma medida de improbabilidade contingente. A especificação referese à padronização de arranjos complexos onde o padrão pode ser recuperado independentemente do arranjo real. Dembski então critica o uso de um algoritmo evolucionário para definir complexidade especificada, visto que para isso existe uma formulação matemática rigorosa.

Dembski se tornou um matemático muito conhecido por sua dedicação intensa às questões da evolução. Os conhecimentos e habilidades adquiridos em estatística supostamente o levaram a crer que a extraordinária diversidade da vida é estatisticamente improvável de ter sido produzida pela seleção natural. Ele critica fortemente a postura científica dos últimos anos, principalmente da biologia evolutiva, que segundo ele, desviouse da busca pela verdade sobre a vida. Também se opõe à presença da teoria da evolução em uma variedade de disciplinas, apresentando o design inteligente como uma alternativa ao materialismo reducionista, conferindo um senso de propósito que o processo evolutivo não guiado carece. Tendo em sua visão o design inteligente como um movimento popular, bem como uma hipótese científica, Dembski afirma trabalhar em prol do processo de desalojamento da evolução do imaginário público (FRAZIER, 2002).

Sobre os simuladores de evolução, como o Avida, Dembski afirma que são incoerentes em relação aos objetivos de provar a funcionalidade do mecanismo darwiniano, uma vez que executam simulações dirigidas por fontes de informações ativas no programa (EWERT, 2009). Sobre o algoritmo da evolução proposto por Chaitin, Dembski aponta deficiências sérias:

"O modelo de Chaitin usa recursos ilimitados, coisas que não existem na realidade, ou são desconhecidas, ou são desvinculadas. [...] Com recursos ilimitados e tempo não limitado, pode-se fazer quase tudo. Pode-se também exceder rapidamente os recursos computacionais do universo conhecido." (EWERT, 2013, p. 4) 
O modelo de Chaitin seria então contraproducente em vigor, pois o mecanismo necessita de condições não realísticas para poder funcionar.

Dembski parece rejeitar qualquer autoria de provas matemáticas absolutas contra o mecanismo darwiniano ou em favor do design inteligente. Em resposta a críticas sobre a "lei de conservação da informação”, ele afirma:

“Eu não estou e nunca estive no negócio de oferecer uma prova matemática rigorosa para a incapacidade de mecanismos materiais gerarem complexidade especificada da mesma forma que nenhum físico está no negócio de oferecer uma prova matemática estrita para a conservação da energia." 8

Entretanto, em Can Evolutionary Algorithms Generate Specified Complexity?, Dembski procura ser rigorosamente formal em demonstrar que a informação encontrada em um organismo vivo não pode ser gerada por um algoritmo evolucionário de modelo darwiniano. Desta forma, com literalidade, ele argumenta que uma fase prebiótica de evolução molecular em uma sopa química jamais poderia ter gerado um organismo vivo a partir do zero, como sugerido pela teoria evolucionária. Na verdade, Dembski demonstra que algoritmos evolucionários não somente são incapazes de descrever a complexidade especificada na origem da vida, mas falham em explicar essa característica na história subsequente dos organismos vivos. No que segue, descrevemos esta argumentação do matemático.

Dembski explica que gerar complexidade especificada por meio de um algoritmo evolucionário é um problema de otimização, em que uma função fitness mede o nível de otimalidade das possíveis soluções do problema. O espaço das soluções deve ser limitado (compacto), por motivos já mencionados, e deve estar munido de uma medida de probabilidade uniforme (invariante), a qual tem o papel de estimar a complexidade de cada solução. O alvo é uma solução com certo nível de otimalidade e, supostamente, tem probabilidade muito pequena, além de ser especificada. Dessa forma, a determinação do alvo pelo algoritmo evolucionário significa geração de complexidade especificada. Agora, um algoritmo evolucionário é um processo estocástico que deve executar um número finito de ações e parar assim que atingir o alvo. Visto que o algoritmo deve atingir o alvo em um número finito de etapas, Dembski fixa um intervalo de números naturais de 1 a $\mathrm{m}$ como conjunto indexador do algoritmo. Ele observa que na maioria dos casos de interesse, o alvo é tão pequeno que a probabilidade de encontrá-lo em $m$ passos de forma aleatória é minúscula (DEMBSKI, 2003, p. 97). Também observa que o sucesso do algoritmo em atingir o alvo depende crucialmente da estrutura da função fitness. O segredo do êxito de alguns algoritmos evolucionários está na escolha adequada da função fitness, que se ajusta bem ao alvo (idem, 1986, pp. 47-48). Este é o principal problema apontado por Dembski, pois a escolha da função fitness requer mais informação ou complexidade especificada do que o alvo original. Além disso, o que é mais desconcertante, o que distingui alvos é exatamente a escolha da função fitness. Isto significa que o problema de encontrar uma

${ }^{8}$ If Only Darwinists Scrutinized Their Own Work as Closely: A Response to 'Erik'. 
determinada sequência de alvos é substituído por um novo problema de encontrar uma correspondente função fitness capaz de localizar o alvo. Mas isto implica que o novo espaço de soluções é a coleção de todas as possíveis funções fitness, que é muito menos tratável do que o espaço original de soluções. Intuitivamente falando, o novo espaço é absurdamente maior do que o espaço inicial.

Esta análise de Dembski revela uma regressão sucessiva em qualquer algoritmo evolucionário. Para se atingir um alvo, o espaço de soluções deve ser substituído sucessivamente por espaços absurdamente mais complicados de lidar, tomando-se espaço de funções sobre espaço de funções, indefinidamente. Este processo regressivo não tem fim e a cada regressão o alvo se torna mais complexo. Isto aponta uma inconsistência na hipótese de que um algoritmo evolucionário eventualmente deve parar seu processo. Esta regressão sucessiva imposta sobre os algoritmos evolucionários é conhecida pelos especialistas como uma caracterização do teorema no-free-lunch, o qual enuncia que nenhum procedimento de busca supera qualquer outro (cf. CULBERSON, 1998). Segundo uma versão genérica desse teorema, a medida de desempenho das possíveis funções fitness é independente dos algoritmos evolucionários. Uma vez que a busca cega sempre constitui um algoritmo evolucionário perfeitamente válido, isso significa que a medida de desempenho de qualquer algoritmo evolucionário nunca é melhor do que a busca cega (DEMBSKI, 2003, p. 103).

Portanto, um algoritmo evolucionário genuinamente darwiniano não pode privilegiar um determinado alvo. A predefinição de uma função fitness no algoritmo atribui de antemão a complexidade especificada no processo. Dessa forma, os algoritmos evolucionários usuais não geram complexidade especificada, mas apenas aproveitam uma já existente. Definitivamente, não há qualquer possibilidade de reduzir o espaço das funções fitness e assim aumentar as chances de um algoritmo evolucionário atingir o alvo sem direcionamento (ibidem, 2003, p. 107). Dembski conclui que um gerador de complexidade deve ter inteligência: "Em todos os casos em que conhecemos o sentido causal de complexidade especificada, um agente inteligente esteve envolvido" (ibidem, 2003, p. 108).

É evidente que nenhum algoritmo evolucionário pode provar um processo evolutivo sem direcionamento inteligente ou planejamento, pois um algoritmo por si mesmo é projetado, sem falar de um algoritmo com um alvo predeterminado. Mas os teóricos darwinistas insistem que a evolução darwiniana da vida real pode sim gerar complexidade especificada. Para contornar problemas como os apresentados por Dembski, pressupõem que a função fitness na evolução biológica segue direta e livremente da sobrevivência diferencial e da reprodução. O replicador irá provar diferentes variantes através de mutação, e então a função fitness selecionará as variantes que constituem uma melhoria na forma de sobreviver e reproduzir. No entanto, segundo Dembski, se o mecanismo darwiniano de sobrevivência diferencial e reprodução é o que de fato impulsiona a evolução biológica em larga escala na natureza, então a função fitness induzida por esse mecanismo tem que ser muito especial e muitas condições prévias precisam ser satisfeitas (ibidem, 2003, p. 110). Na verdade, deve-se pressupor todos os princípios antrópicos e o ajuste fino cosmológico, que levam muitos físicos a ver o design no universo. Cosmologia, astrofísica e geologia não conseguem esgotar as condições que 
uma função fitness deve satisfazer se for para fazer o grande sucesso que vemos no planeta Terra. Além disso, o mecanismo de cópia de DNA de replicadores deve ser suficientemente confiável para evitar catástrofes de erros. Salvo um alto grau de confiabilidade, os replicadores serão extintos ou se chafurdarão interminavelmente em um estado de baixa complexidade - basicamente apenas complexidade suficiente para evitar a catástrofe de erro.

Enfim, se a espetacular diversidade de formas vivas observadas na Terra é adequadamente atribuída a uma forma darwiniana de evolução, então o catálogo de condições que a função fitness induzida pela sobrevivência diferencial e reprodução precisa satisfazer é absurdamente vasto, exigindo uma grande quantidade de complexidade especificada. Segundo o matemático, a função fitness é uma montagem finamente trabalhada de gradientes suaves que pressupõe muita complexidade especificada atribuída previamente ao processo, e a única explicação plausível para tal pressuposição seria a influência de um agente inteligente na direção do processo.

\section{COMENTÁRIOS}

O matemático Ian Stewart propôs questões de difícil tratamento pelas vias do mecanismo darwiniano: origem, vida, inteligência, pensamento, cultura e livre arbítrio. Ele discutiu a evolução destas propriedades em consonância com a evolução do universo todo, apontando a necessidade de uma lei que interpreta o crescimento progressivo da complexidade. Propôs que mente é qualquer processo que ocorre em estruturas feitas de matéria comum, que interage com o meio ambiente e cujo comportamento evolui para imitar, modelar e manipular processos naturais. As interações com o meio externo revelam uma coevolução mútua entre dois processos inicialmente separados. A inteligência humana e a cultura humana constituem um exemplo notável de coevolução mútua, interpretado pela evolução de maneiras não genéticas, mas pelas transmissões de conhecimentos, hábitos e comportamentos. O mecanismo darwiniano usual é genocêntrico e, portanto, não pode descrever estas interações fundamentais da evolução. Desta forma, o trabalho de Stewart contribui significativamente com a teoria evolucionária, oferecendo uma tratativa que vai além das potencialidades da teoria de Darwin.

Entretanto, existem obstáculos muito difíceis de serem vencidos. A abordagem reducionista tradicional da ciência não pode explicar o comportamento emergente de sistemas auto-organizados, o que deixa de fora, por exemplo, a cumplicidade da inteligência e da cultura humana. Todavia, fazendo uso de variados conceitos matemáticos de sistemas dinâmicos, Stewart notificou que modelos baseados em fenótipos sugerem que a evolução pode ser vista como um sistema auto-organizante, possibilitando a inclusão de novas abordagens para as pressuposições de aptidão e seleção de espécies. Stewart também contribui com o apaziguamento das controversas envolvendo os pressupostos evolucionistas e a segunda lei da termodinâmica. Salientou que esta lei física é inaplicável na biologia evolutiva, havendo a necessidade de uma "segunda lei da gravidade" em coerência com uma "quarta lei da termodinâmica", que rege o evidente crescimento de complexidade na natureza.

Com a perspectiva de formalidade matemática para estudos da evolução, o 
matemático Gregory Chaitin propôs a teoria da informação algorítmica para solucionar problemas de biologia evolutiva. Com base na teoria da evolução dos softwares artificiais, a metabiologia, Chaitin desenvolveu um modelo algorítmico para o mecanismo darwiniano. Seu entusiasmo pela matemática proporcionou uma forma bem ousada de provar a teoria de Darwin, observando que se a teoria darwiniana é de fato fundamental como usualmente se pensa, então deve existir uma teoria matemática da evolução que capture a essência do mecanismo darwiniano e o desenvolva matematicamente. Embora Chaitin esteja inclinado a apostar em Darwin, seus esforços mais indicam o quanto é difícil ratificar a teoria darwiniana. O principal problema do modelo evolucionário de Chaitin é sua fuga da verdade prática. De fato, na metabiologia, a lista de defeitos é extensa: os sistemas físicos são desconsiderados; o domínio de recursos é ilimitado; o tempo é infinito; as mutações somente influenciam positivamente os processos; não há presença de população; etc.. Além disso, a característica genocêntrica do mecanismo darwiniano obrigou Chaitin a alterar radicalmente a definição de vida, excluindo a variação individual e a reprodução. O matemático então reconhece que o cenário de adaptação tem que ser muito especial para a evolução darwiniana funcionar, mas tem esperança de que seu modelo irá alavancar trabalhos mais completos futuramente. Para o filósofo Radosław Siedliński, no entanto, uma teoria matemática geral da evolução darwiniana parece ser muito improvável de se realizar.

Para decretar uma necessidade indispensável de reajustes no modelo darwiniano da evolução, o matemático Willian Dembski demonstrou com rigorosidade, e de forma geral, que os algoritmos evolucionários sem direcionamento não podem gerar complexidade especificada, o que inviabiliza toda tentativa de provar a funcionalidade do mecanismo darwiniano por meio de algoritmos. Esta constatação compartilha com o resultado de Kimura (1983), o qual assegura que a evolução molecular deve ser totalmente estocástica, o que deixa o surgimento de estruturas biológicas complexas um enigma. ${ }^{9}$

\section{CONCLUSÃO}

Os avanços da teoria evolucionária não acrescentaram conhecimento substancial além da constatação de que organismos vivos são extremamente complexos. Mas se tornou muito cômodo assumir o poder da evolução em vez de se analisar a carga enorme de complexidade existente no surgimento de uma espécie. Neste ponto, encontra-se a principal contribuição dos matemáticos, os quais não se conformaram com pressuposições informais e se empenharam no estudo enfadonho da complexidade. Pode-se perceber nitidamente que os matemáticos têm mais facilidade em encontrar problemas do que soluções para a teoria darwiniana. Todavia, as perspectivas inovadoras do trabalho de Stewart, o entusiasmo das ideias de Chaitin e a proposta do planejamento inteligente de Dembski ascendem uma esperança para uma teoria da evolução estimável por físicos, biólogos, filósofos e matemáticos.

\footnotetext{
${ }^{9} \mathrm{O}$ trabalho de Kimura obteve respeito pelos darwinistas, como se pode ver em "How to Attack Neo-Darwinism and Still End Up in Evolution Textbooks: The Neutralist-Selectionist Controversy", review of The Neutral Theory of Molecular Evolution, by Motoo Kimura, <http://wasdarwinwrong.com/Kortho37>, acessado em 20 de março de 2020.
}

RBHM, Vol. 21, nº 41, pp. 89-108, 2021 


\section{Bibliografia}

CHAITIN, Gregory. 2003. From Philosophy to Program Size. arXiv:math/0303352.

CHAITIN, Gregory. 2003. Randomness and Mathematical Proof. In: From Complexity to Life: On the Emergence of Life and Meaning. New York: Oxford University Press, pp. 1933.

CHAITIN, Gregory. 2012. Proving Darwin. Making Biology Mathematical. New York: Pantheon Books.

CULBERSON, Joseph. On the Futility of Blind Search: An Algorithmic View of 'No Free Lunch’. Evolutionary Computation, vol. 6, n. 2, p. 109-127, 1998.

DAVIES, Paul. 2000. The Fifth Miracle: the Search for the Origen of Life. New York: Simon \& Schuster.

DAVIES, Paul. 2003. Toward an Emergentist Worldview In: From Complexity to Life: On the Emergence of Life and Meaning. New York: Oxford University Press, pp. 3-16.

DAWKINS, Richard. 1986. The Blind Watchmaker. New York: Norton.

DEMBSKI, William. 1988. Chaos, Uniform Probability, and Weak Convergence. Tese. Chicago: University of Chicago, Department of Mathematics.

DEMBSKI, William. 1991. Randomness by Design. Noûs, vol. 25, p. 75-106.

DEMBSKI, William. 1994. On the Very Possibility of Inteligent Design. In: The Creation Hypothesis: Scientific Evidence for an Intelligent Designer. MORELAND, J. P. (editor). Madison: IVP Books, pp. 113-138.

DEMBSKI, William. 1998. The Design Inference: Eliminating Chance through Small Probabilities. New York: Cambridge University Press.

DEMBSKI, William. 2002. If Only Darwinists Scrutinized Their Own Work as Closely: A Response to 'Erik', https://billdembski.com/documents/2002.08.Erik_Response.htm, Acessado em 21 de março de 2020.

DEMBSKI, William. 2003. Can Evolutionary Algorithms Generate Specified Complexity? In: From Complexity to Life: On the Emergence of Life and Meaning. New York: Oxford University Press, pp. 93-113. 
EWERT, Winston, DEMBSKI, William e MARKS, Robert. 2009. Evolutionary Synthesis of Nand Logic: Dissecting a Digital Organism. Proceedings of the 2009 IEEE International Conference on Systems, Man, and Cybernetics. San Antonio, TX: IEEE Systems, Man, and Cybernetics Society. pp. 3047-3053.

EWERT, Winston, DEMBSKI, William e MARKS, Robert. 2013. Active Information in Metabiology. BIO-Complexity, vol. 4, p. 1-10.

FRAZIER, Kendrick e RADFORD, Benjamin. 2002. Fourth World Skeptics Conference in Burbank a Lively Foment of Ideas. Skeptical Inquirer, vol. 26, n. 5, pp. 5-12.

KAUFFMAN, Stuart. 2000. Investigations: Scope for a Possible "Fourth Law" of Thermodynamics for Non-Equilibrium Systems. New York: Oxford University Press.

KAUFFMAN, Stuart. 2003. The Emergence of Autonomous Agents In: From Complexity to Life: On the Emergence of Life and Meaning. New York: Oxford University Press, pp. 4771.

KIMURA, Motoo. 1983. The Neutral Theory of Molecular Evolution, Cambridge: Cambridge University Press.

MAYNARD SMITH, J. 1986. The Problems of Biology. New York: Oxford University Press.

MITCHELL, Melanie. 1997. Review of "Figments of Reality" by Ian Stewart and Jack Cohen. New Scientist, August 11, 1997.

SIEDLIŃSKI, Rodoslaw. 2016. Turing machines and evolution. A critique of Gregory Chaitin's metabiology. Studies in Logic, Grammar and Rhetoric, vol. 48, n. 61, pp. 133150 .

SKÅR, John; COVENEY, Peter; STEWART, Ian. 2003. Self-organization in evolution: $a$ mathematical perspective. 361. Philosophical Transactions of the Royal Society of London. Series A: Mathematical, Physical and Engineering Sciences.

SOUZA, Josiney. 2016. Os matemáticos da evolução. Revista Eletrônica Espaço Teológico, vol. 10, n. 17, pp. 54-70.

STEWART, Ian. 1969. Subideals of Lie algebras. Tese. Warwick: University of Warwick.

STEWART, Ian N., 2003. Second Law of Gravitics and Fourth Law of Thermodynamics. In: From Complexity to Life: On the Emergence of Life and Meaning. New York: Oxford University Press, pp. 114-150. 
STEWART, Ian e COHEN, J., 1997. Figments of Reality: The Evolution of the Curious Mind. Cambridge: Cambridge University Press.

\section{Josiney Alves de Souza}

Departamento de Matemática - UEM - campus de Maringá - Brasil

E-mail: jasouza3@uem.br 